\title{
Eduardo JimÉnez Rayado, AGUa Y SOCIEDAD EN Madrid DURANTE la EDAD MEDIA, CÁdIZ, Editorial UNIVERSIDAD DE CÁdIZ, 2021, 340 PÁGs. ISBN: 978-84-9828-833-9.
}

\author{
JaVier VillaVerde Moreno \\ Universidad Rey Juan Carlos
}

No deja de ser sorprendente que en estos tiempos salga a la luz una monografía sobre la historia ciudad de Madrid, cuando parecía que el protagonismo de la capital de España no podía estar más sobredimensionado en la palestra mediática. Y, tampoco, deja de ser sorprendente que en medio de este clima enrarecido que da fuelle al orgullo de una ciudad como Madrid, el autor de este libro, Eduardo Jiménez Rayado, haga énfasis en los orígenes modestos y humildes de una villa en la que, hasta el establecimiento definitivo de la corte en el siglo XVI, vivió ajena a los delirios de grandeza de élites y jerarquías. La obra de Jiménez lleva por título Agua y sociedad en Madrid durante la Edad Media y no ha lugar a error, pues enuncia los elementos principales que serán objeto de su análisis: el agua como vertebradora del medio natural, urbano y social del Madrid medieval y el desarrollo de la sociedad matritense y su interacción con el líquido elemento. Apuntamos, precisamente, que una de las grandes virtudes de este trabajo es la interrelación y conexión de estos tres objetos (agua, ciudad y sociedad) para la consecución de estudio integrador y cohesionado, que dota de mayores dosis de solidez argumentativa, por supuesto, desde el análisis científico.

Desde nuestra perspectiva, esta obra señala indirectamente al desconocimiento generalizado que abunda en la sociedad actual sobre los orígenes de Madrid. Una carencia que este libro procura saciar con un repertorio sólido de fuentes documentales, arqueológicas, geográficas, e incluso medioambientales, y haciendo gala de una metodología crítica, demostrable y transparente, aun admitiendo las enormes dificultades de emprender un estudio con escasez de datos sobre el periodo que se analiza: el Madrid medieval. La lectura es accesible a un público general y el propósito del autor es transferir los resultados de su investigación para evitar la falacia y el malentendido. En palabras del propio Jiménez: "reconocer y hacer presente ese pasado nos hace inmunes a pandemias no tan mortíferas pero igualmente peligrosas" (p. 305).

Es justo subrayar el mérito que tiene reconstruir la vieja ciudad matritense a través de su relación con el agua, pues el autor se ha enfrentado, principalmente, a dos grandes obstáculos. Por un lado, a la ya mencionada exigüidad de fuentes. Por otro, a la oculta- 
ción del original aspecto de la ciudad medieval a partir del siglo XVI, fecha en la que Madrid pasó de ser un humilde poblamiento de segunda fila a la capital de un imperio hegemónico en el mundo. Por tanto, es doble el esfuerzo del autor, primero, por el excelente aprovechamiento de las pocas fuentes medievales (complementariamente, también fuentes modernas) no solo por la información que ofrecen, sino interpretando aquello que no reflejan, y en segundo orden, por destapar las raíces islámicas y beréberes de Madrid, que no con poca intención quedaron soterradas bajo un imaginario de tintes clásicos y católicos al servicio de la corte de la Monarquía Hispánica.

El libro presenta una estructura de nueve capítulos. Los seis primeros corresponden al agua como significante en Madrid, es decir, a su dimensión material: desde los recursos hídricos disponibles, la distribución de fuentes y manaderos, el sistema de abastecimiento, la explotación económica la evacuación de aguas y, también, su fuerza destructora. Los últimos tres capítulos, por su parte, corresponden al significado del agua para la sociedad, a su dimensión simbólica, religiosa e identitaria.

Haremos un breve resumen, capítulo a capítulo. En el primero de ellos, se reconstruye el mapa hidrológico de Madrid, demostrando que los primitivos habitantes de la capital tuvieron a su disposición excelentes y abundantes aguas tanto superficiales como subterráneas, destacando el arroyo de San Pedro (que transcurría por la actual calle Segovia hacia el Manzanares). En el segundo capítulo, un paso más allá, el autor continúa moldeando el paisaje del Madrid medieval urbano, y explicando cómo el agua, con sus cursos fluviales, sus manantiales o sus capas freáticas es el "principal factor dentro de las características naturales que condicionan el desarrollo de un asentamiento urbano" (p. 48). En el caso de Madrid, esta afirmación se demuestra sobradamente.

El tercer capítulo merece una mención aparte. Es uno de los apartados más críticos, que aporta una nueva teoría con respecto al abastecimiento y distribución del agua por la antigua población madrileña. Expone la hipótesis que, hasta hace pocas décadas, fue hegemónica en la historiografía y arqueología españolas: que el Madrid medieval contaba con canales subterráneos o viajes de agua construidos en era islámica. Sin embargo, para el autor no hay base documental ni arqueológica suficiente para mantener esta teoría, además, aporta argumentos muy bien formulados para rebatirla y llega a la conclusión de que la pequeña medina maŷrití no necesitaba obras de ingeniería tan complejas y costosas para abastecer a su población e irrigar sus huertas, pues la cantidad de agua presente en sus arroyos, pozos y manantiales era más que suficiente.

En el cuarto capítulo, se exponen una serie de actividades económicas basadas en la explotación del agua. Es llamativa la gran variedad de oficios y rentas que dependen y dependían de suministro de agua, que nos ayuda a tomar conciencia de esta realidad tan presente aún en nuestras vidas. En el Madrid medieval fue destacable la industria alfarera y peletera, ambas consumidoras de agua para sus fines. Precisamente, el autor incide en varias ocasiones en la importancia de las tenerías madrileñas, una actividad de la que se conservan un buen número de datos en los archivos municipales. 
El capítulo quinto se dedica a la higiene y evacuación de aguas. Jiménez trata de localizar los baños cuyo origen islámico queda todavía sin determinar, aunque sí queda clara en la documentación la referencia a dichos baños y su uso por parte de la población, especialmente mudéjar y judía. También se expone en este apartado el problema endémico de Madrid con la evacuación de aguas sucias, problema para el que siempre eran activadas las políticas de saneamiento, pero nunca las de prevención.

El sexto capítulo aborda los inconvenientes del agua en la vida cotidiana del Madrid medieval. Hasta ahora, se ha tratado al agua como aliada del ser humano, pero aquí se desenvuelve su otra cara, la de su capacidad destructiva. De este apartado cabría destacar la constante reparación de puentes dañados por diferentes causas, como las crecidas del río o el paso de carros. Este y otros inconvenientes, como el de las aguas contaminadas por la acción humana, dibujan una imagen fehaciente de los problemas cotidianos de la vida madrileña en los siglos medievales.

A partir del capítulo séptimo cambia el enfoque del trabajo, pues se pasa a analizar el imaginario colectivo del agua para los madrileños. Más adelante comentaremos uno de los aciertos de este libro referente al origen del nombre de la ciudad. Por lo demás, en este apartado el autor reflexiona sobre los elementos sobre los que se construyó la identidad y el orgullo cívico de Madrid. No fue sobre ninguna leyenda, o hecho destacable en la historia, dados los orígenes humildes de la villa. Por tanto, se tendió a identificar Madrid con su principal recurso natural: el agua. De ahí el lema "fui sobre agua edificada, mis muros de fuego son".

En el capítulo octavo se recogen una serie de tradiciones religiosas asociadas al agua, como los ritos de purificación, muy presentes en la villa madrileña por la existencia de comunidades musulmanas y judías, y también ritos propiciatorios de la lluvia. De lo más destacado de este apartado es la defensa por parte del autor de un fenómeno de absorción por parte del cristianismo de cierto ritos y creencias previas beréberes e islámicas. Y, finalmente, en el capítulo noveno el autor reflexiona sobra la importancia del agua en la mentalidad medieval. Desde su capacidad para representar el paisaje, pasando por los poderes mágicos y taumatúrgicos atribuidos a ella, así como su uso por parte de las élites para representar su riqueza y poderío. En suma, muestra los variados significados que el hombre y la mujer medievales hallaban en el preciado líquido.

La obra supone, por tanto, un avance en el conocimiento del pasado de Madrid y, por otra parte, una referencia para los estudios del agua en las sociedades medievales. Tampoco se quedan cortas las aportaciones de Jiménez al debate historiográfico planteado años atrás con respecto a los orígenes del nombre de la ciudad. En este sentido, el autor ofrece interesantes y novedosas perspectivas no observadas con anterioridad por parte de los especialistas. Su hipótesis parte de la dotación de un mayor protagonismo a la comunidad beréber, norteafricana y campesina, asentada en Madrid a partir del siglo IX, los primeros pobladores de la que será capital de España, y la huella que han podido dejar estos tanto en el nombre de la ciudad (el sufijo -it de Mayrit) como en tradiciones religiosas como las rogativas de agua para pedir la lluvia o la importancia 
de los santones y curanderos a los que se piden favores y milagros. De hecho, otra de las hipótesis valientes de Jiménez es la búsqueda de una posible conexión entre esta tradición beréber y la figura milagrosa de Isidro Labrador.

Junto con la comunidad beréber, a la que se atribuye un papel destacable en la historia de Madrid en este libro, el autor también pone el foco en las mujeres. Resulta exquisito el cuidado con el que trata a este importante sector de la población medieval de Madrid, y no pierde nunca la oportunidad de recordar el necesario esfuerzo del historiador para recuperar el pasado de cierta parte de la sociedad que ha pasado desapercibida de la atención tanto general como académica. En este caso, Jiménez apunta certeramente a la estrecha relación del agua y las mujeres, pues su conjunción generaba espacios femeninos como las fuentes y lavaderos, actividades económicas básicas como el transporte de agua o el lavado y la consecuente creación de símbolos y tradiciones que refuerzan el vínculo de las mujeres con el elemento líquido. Así, ejemplos como el de María de la Cabeza o la Virgen de Atocha muestran esa unión de elementos femeninos e hidrológicos a través de relatos tradicionales como los milagros para evitar catástrofes causadas por la lluvia, o, por el contrario, para evocarla.

No podemos acabar este breve comentario sin reclamar un poco más de cuidado con algunos términos en lengua árabe, más si cabe, cuando en este estudio se apela directamente al núcleo urbano islámico de Madrid y una parte importante de sus potenciales lectores pertenecen al ámbito arabista y medievalista andalusí. Nos referimos a algunas palabras que no se transcriben del modo más correcto como hamman que confunde la $m$ final por una $n$ y debería transcribirse en singular hammām y, en plural, hammāmāt. O confundiendo la $q \bar{a} f$ con la $k \bar{a} f$ en sakka "aguador" (p. 165), que en árabe es saqqā'. Consciente del esfuerzo añadido que conlleva la corrección léxica árabe, no deja de ser un aspecto que debe cuidarse y seguramente que mejoraría la calidad, aportaría un mayor rigor, y subrayaría la importancia de una lengua esencial para recomponer el pasado matritense. 